\title{
Exploring emotions and the economy: new contributions from sociological theory
}

\author{
Mabel Berezin
}

Published online: 11 April 2009

(C) Springer Science + Business Media B.V. 2009

\section{Emotional metaphors and economic facts: who's afraid of the Dow Jones?}

In fall of 2008, global economic depression seemed a viable future possibility. As the U.S. stock market went into in free fall and major financial institutions collapsed on an almost daily basis, a colleague casually mentioned the volatility of the "fear index" as a measure of financial instability. My initial reaction was that my colleague was joking. I soon learned that the "fear index" was not a joke, rather it was a metaphor that stock traders and others in finance use for the VIX which is the Chicago Board of Options Exchange Volatility Index. The economist Robert E. Whaley developed the index in 1993 at the request of the Chicago Board. Its purpose is to measure unusual swings in the Stock Market over a 30 day period. It is a daily real time fluctuation calculated from the moment that the market opens. A high figure suggests a more volatile market and more risk for investors. Prior to fall 2008, the big spikes in the index had occurred in 1998 after the collapse of the Long Term Capital Management hedge fund and in 2001 after the attacks on the World Trade Center. The lows were from roughly 1993 to 1996 and 2004 to $2006{ }^{1}$

On September 14, 2008, the United States government decided not to rescue the large financial house Lehman Brothers thus forcing it to declare bankruptcy on the following day. The failure of Lehman Brothers was the first event in a series of events that analysts have described as the worst financial crisis since the world depression of the 1930s. From mid-September onwards, fear and its various synonyms became constant descriptors from Wall Street to Main Street-a trope that American politicians and pundits in the intensity of a heated Presidential campaign became fond of invoking for the public. Fear, anxiety, and panic dominated not only

\footnotetext{
${ }^{1}$ For an academic discussion of the significance of economic indicators see De Santos (2007). For a discussion of emotion in the financial services sector, see Hassoun (2005) and Zaloom (2006).
}

M. Berezin $(\bowtie)$

Sociology Department, Cornell University, 346 Uris Hall, Ithaca, NY 14853, USA

e-mail: mmb39@cornell.edu 
public representations of the financial crisis, but also described the emotions of real people.

A Lexis Nexis search of English language press between September 9 and December 9, 2008, on the terms "fear, financial, anxiety, and panic" yielded 118 articles. The search with those keywords captured only a percentage of what was written and reported in fall 2008. It did not include tabloid, television, Internet news, or international media. A sampling of the yield on this admittedly limited search is telling. Discussion was not limited to the financial and business pages of major newspapers. In The London Times, "Infected by Mass Anxiety," headlined under the rubric of "Body and Soul"-presumably a health section. Britain's Independent warned, "We are Living in the Great Age of Panic." Newsweek magazine devoted a cover issue to the "Anatomy of Fear;" The Economist's cover headlined, "World on Edge." USA Today warned, "Financial Fears Send Nation's Stress Soaring; Consumers are on Edge as Bad News Piles on Top of Bad News." The New Yorker magazine spoke to "The Rationality of Panic." On an almost optimistic note, the Montreal Gazette opined, "Fear Factor: The Emerging Science of Neuroeconomics Suggests that Market Panics and Euphoria are Largely in Our Heads." The Business Section in the Sunday edition of the New York Times began devoting weekly articles to the crisis with experts such as Robert Shiller and Robert Frank dispensing analysis. Articles moralized "Before Fear there was Foolishness," or warned, "The Mood Always Matters, So Restore Confidence First." In December 2008, financial journalist and author, Michael Lewis (2008) published a book, Panic: The Story of Modern Financial Insanity whose title captured the emotional valence of the three months that had passed since the failure of Lehman Brothers.

The language of fear, stress, panic that has permeated discussion of the 2008 financial crisis in various media from the press to the blogosphere underscores a salient feature of the essays that follow. Emotion is a constitutive dimension of the economy - even if we only collectively recognize it in times of crisis. Moreover, the metaphors of emotion that dominate descriptions of the current crisis remind us of what social scientists (and some economists) have been arguing for the last ten years or so - the rationality and the economy more often represent an odd coupling than a harmonious marriage. ${ }^{2}$ Yet a paradox remains. Despite evidence to the contrary, the idea that the economy displays rationality and regularity remains powerful. The power of this economic idea provides the central problematic that this special issue attempts to address. ${ }^{3}$ The assumption of equilibrium and self regulation colored my initial perception of the "fear index" as a joke. Beginning with Freud's (1905) classic essay on wit and the unconscious, jokes are a staple of psychological, sociological and anthropological theorizing. Jokes are instructive when attempting to theorize the relation between macro level structures and micro level perceptions.

Anthropologist Mary Douglas (1975) is particularly germane in this regard. She argues that ". . . a joke cannot be perceived unless it corresponds to the form of the social experience: but I $[M D]$ would go a step further and even suggest that the experience of a joke form in the social structure calls imperatively for the joke form to express it (153-54)." Douglas continues: "Jokes being themselves a play upon

\footnotetext{
${ }^{2}$ See for example, Shiller (2000); Frank (1988); Etzioni (1988); Smelser (1995); Massey (2002).

3 The essays in Hall (1989) address the power of economic ideas, a notion that goes back to Keynes.
} 
forms can well serve to express something about social forms.... the joke connects and disorganizes. It attacks sense and hierarchy (156)." Macro level structures that we experience as part of daily life such as the economy are analogous to "social forms." Our expectation of dis-order in the face of a rhetoric of order is an attack on standard discourse on economics as a science. In order to "get" the meaning of a joke, Douglas argues that the individual or the group has to understand its subversive elements. They must belong to a community of shared culture where meaning is implicit and thus unspoken - until challenged in the form of a joke.

My initial reaction to the "fear index" suggests my implicit assumptions about the financial community. I assumed that the community of high status financial players experienced or made "sense" of the economy as scientific, rational, and unemotional - an entity that generated reasoned behavior not emotional reactions. But the fact that economists and financial operatives would label the volatility index the "fear index" makes explicit an implicit agreement within the financial community and among economic experts that the economy is indeed-volatile, irrational and generative of emotional behavior among investors.

Metaphors are not simply artfully arranged words - rather they are grounded in social experience and social referents. Emotional metaphors about the economy reveal economic facts. In the current situation, these facts include rising unemployment, roller coaster stock market values, home owner mortgage foreclosures, and global financial disarray. We may think of these economic facts much in the same way that Emile Durkheim (1894) described "social facts," that is as "ways of acting, thinking, and feeling that present the noteworthy property of existing outside the individual consciousness (2)." Social facts are ". . . every way of acting, fixed or not, capable of exercising on the individual an external constraint; or again, every way of acting which is general throughout a given society, while at the same time existing in its own right independent of its individual manifestations (13)."

Social facts include collective phenomena - the law, the economy, the unemployment rate-as well as the individual and collective perception of them. Thus, Durkheim argues that a "social fact" is a structural and a psychological fact that goes beyond structure. He labels this combination of material and mental phenomena as "social currents" and describes them as ". . . the great movements of enthusiasm, indignation, and pity in a crowd do not originate in any one of the particular individual consciousnesses. They come to each one of us from without and can carry us away in spite of ourselves. They come to each one of us from without and can carry us away in spite of ourselves. Of course, it may happen that, in abandoning myself to them unreservedly, I do not feel the pressure they exert upon me. But it is revealed as soon as I try to resist them. Let an individual attempt to oppose one of these collective manifestations, and the emotions that he denies will turn against him (4-5)."

Economics facts rather than economics or the economy per se are social facts that combine emotional valence, cultural meanings and institutional arrangements. While economists have focused upon the structure of economic relations, sociologists have typically turned their attention to institutions and more recently issues of culture. When we add emotions to the mix, we open up a new interdisciplinary arena with a vastly enlarged playing field. The essays in this special issue attempt to elucidate 
facets of this expansion, to suggest new connections among different approaches as well as to forge a uniquely sociological approach.

In an earlier essay, on emotions and the economy (Berezin 2005), I argued that with the exception of the pioneering work of sociologists Arlie Hochschild (1979, 1983); economist Robert Frank (1988) and to some extent social scientist Jon Elster (1996, 1999), emotions while not absent, were more appropriately in "disciplinary exile" within the social sciences. Much has changed in a short time span. Social scientists of all stripes have become interested in the role of emotion. ${ }^{4}$ In 2004, a symposium held in Amsterdam on the subject of "Feelings and Emotions (Manstead et al. 2004)" included participation from natural and social scientists across a range of sub-disciplines. In my own primary field, politics, emotion is firmly on the research agenda. ${ }^{5}$ Economic sociology has also moved forward in this area. New work on emotion in economic sociology includes, but is by no means limited to, the following scholars. Zelizer's (2005) book on marriage continues her study of the transaction price associated with intimate relations. Illouz's (2007) study of capitalism as emotionally "cold" coupled with her work (2008) on markets of selfhelp place the economy and the personal in synchrony with each other. Pixley's (2004) work on global markets links the world of finance to the feeling of emotion. Barbalet (1998) has developed an approach to a macro sociology of emotions that he (2008) has recently expanded to a special look at Max Weber's theory of "passion and profits."

The essays in this special issue focus on new approaches. They are not review essays and they do not capture the work of every scholar who is contributing to this continually evolving and exciting sub-field. With the exception of Nina Bandelj who adds a new voice to the subject, the contributors to this special issue, Jack Barbalet, Jocelyn Pixley, Eva Illouz and her collaborator Shoshannah Finkelman are established figures in the study of the intersection of emotion with macro level societal structures. Their contributions to this special issue bring their individual theoretical approaches to bear on the topic of economy and emotion in new and challenging ways.

For the remainder of this introduction, I lay out what I see as some of the principle issues that sociologists who care about emotion must address and then discuss briefly how the contributions fit into the apparatus.

\section{Emotion and economy: disciplinary paths and analytic possibilities}

From its inception, analysts compared the 2008 economic crisis to the Great Depression of the inter-war years. Often invoking Franklin D. Roosevelt, they point to his inaugural address in 1933 when he said ". . . let me assert my firm belief that the only thing we have to fear is fear itself - nameless, unreasoning, unjustified terror which paralyzes needed efforts to convert retreat into advance." (http://www.

\footnotetext{
${ }^{4}$ Lawler (2001) is the seminal work in social psychology. Turner and Stets (2006) have summarized new directions in the field but they are not especially interdisciplinary in their review.

${ }^{5}$ See McDermott (2004); Berezin (2006); Emirbayer and Goldberg (2005); as well as the essays in Neuman et al. (2007).
} 
americanrhetoric.com/speeches/fdrfirstinaugural.html) Pundits and academics often cite "nothing to fear but fear itself," but usually overlook the second half of the sentence. Roosevelt was trying to keep Americans confident and to shore up their hearts and minds for the work ahead. But he was also warning them against the paralysis of fear. Roosevelt's agenda was political and practical. He wanted to solve the economic challenges that the great depression presented to millions of American citizens. But he makes an unintended crucial point for social theory-that is the necessary connection between emotion and action.

The principal assumption that governs the discussion that follows is that individual and collective actions are central to social analysis. While it is hardly novel to underscore the importance of action, which after all lies at the core of Parsons' (1937) as well as Coleman's (1990) work, emotion is crucial for interpreting both the means and the ends of action. Except for choice theoretic approaches to social and economic behavior, action is often implicit rather than explicit in discussions of emotion. Neuroscientists, economists, psychologists, and moral philosophers, as well as social scientists have engaged emotions. The various disciplinary approaches to emotion have points of confluence as well as divergence. The relation between emotion and action that is germane to all sub-fields of sociology, not only economic sociology, serves as an analytic scaffolding for the discussion of diverse disciplinary paths that follows.

In an earlier article, I argued that "four relevant distinctions" are discernible from parsing the various literatures of emotion (Berezin 2005). Drawing upon those earlier insights, I map the analytic possibilities that an interdisciplinary approach to emotion offers and try to tease out where sociology's distinct contributions may lie. The "relevant distinctions" begin below.

(1) Emotion is first a physical and then a psychological state Neuroscience (Frijda 1993; Mendoza and Ruys 2001; McDermott 2004) is the disciplinary site of much innovative contemporary work on emotion. Neuroscientist Antonio Damasio (1994, 1999) makes the important point that emotion is first a physical feeling that we secondarily articulate as a cognition. Cognition, the second step in emotion, is where culture and historical specificity as well as institutional realms matter. We experience emotion as a physical state-elation, weeping, nausea. Even autoimmune disease, where the body literally turns upon itself, plausibly signals the repression of emotion. The physical experience of emotion is ontologically different from the recognition (cognition) of emotion and the actions that we take in response to our experienced emotions. Social scientists often overlook this distinction and bypass the physical dimension of emotion.

(2) Emotion is constitutive of human nature and by inference constitutive of social life Charles Darwin (1872) made the classic argument that even animals have emotions. Classical studies of human nature beginning in the $18^{\text {th }}$ century understood the absence of emotion and affect as moral and social death. Emotion's relation to ethics or morality and human nature persists to this day, when emotion is the province of moral philosophy as well as psychology (for example, De Sousa 1980; Pizarro 2000; D'Arms and Jacobsen 2000; Greenspan 2000; Nussbaum 2001). Having emotions is natural, that is biological; channeling emotions is moral and 
social. While individuals would not want to live in a state of continuing emotional upheaval, perfect equilibrium (an economist's and rational choice theorist's heaven) would be equally dysfunctional. Economist Robert Frank's $(1988,1993)$ arguments that emotions are rational are based on the unstated assumption that social equilibrium takes away from rather than enhances social and economic innovation. The creative (i.e., innovative and productive) social and economic actor follows his or her passions beyond reason.

(3) Emotion is not culture and vice versa Emotion and culture are interconnected but they should be kept analytically distinct. Culture, norms, values, effect the expression of emotion but not the reality of the emotion, or norms or values (Shweder 1993). Culture affects practices within different economic institutions, as well as the organization and practice of economic life (Middleton 1989).

(4) Trust and Risk are perceptions not emotions Trust is a perception or a cognitive act. Emotion may influence the formation of those cognitions and the resultant mental state of trust but emotion and trust are not co-terminus entities. It is important to make this distinction because trust in the literature on economics and society is sometimes treated (erroneously according to this author) as an emotion. This is a particularly sticky issue that Barbalet (this volume) takes up in great detail. In general, I follow Coleman (1990), whose discussion of trust and risk clearly links them to the problem of action even though emotions may be built into the action. Coleman argues that trust is a "bet on the future" that we place with respect to knowledge that we have about past actions. Past experience, both with our own internal psyches as well as with others, determine our assessment of trust and risk in various situations. Past experience also includes collective experience and it is here where culture intervenes.

Trust is a judgment that we make about actions. ${ }^{6}$ Culture influences how we make those judgments. All actions have a degree of uncertainty built into themeven the most routine. The concept of accident is the recognition of the uncertainty that underlies even the most mundane and routine situations. Trust and risk are directly proportional to each other. Generalized trust informs actions that individuals and collectivities repeat day after day because they are low risk situations. In the absence of information, we may decide to act on little or no information and follow what Elster (1996) describes as "gut feelings." According to Coleman (1990), time is constitutive of trust. Misplaced trust is an error that results from the failure to give adequate time to decision making. Coleman's example of a young woman who does not allow sufficient time to investigate a young man who offers to walk her home and subsequently attacks her (pp. 91-108) underscores the relation between time and trust.

In its purist form, emotion and economy should focus on the non-cognitive dimensions of economic action. But this is impractical and arguably outside the realm of social or moral science. The more typical analytic path is: emotioncognition-action. Much of the social science literature that focuses on emotion

\footnotetext{
${ }^{6}$ See for example, the collection of essays in Cook (2001).
} 


\section{Emotion and Action: Analytic Possibilities}

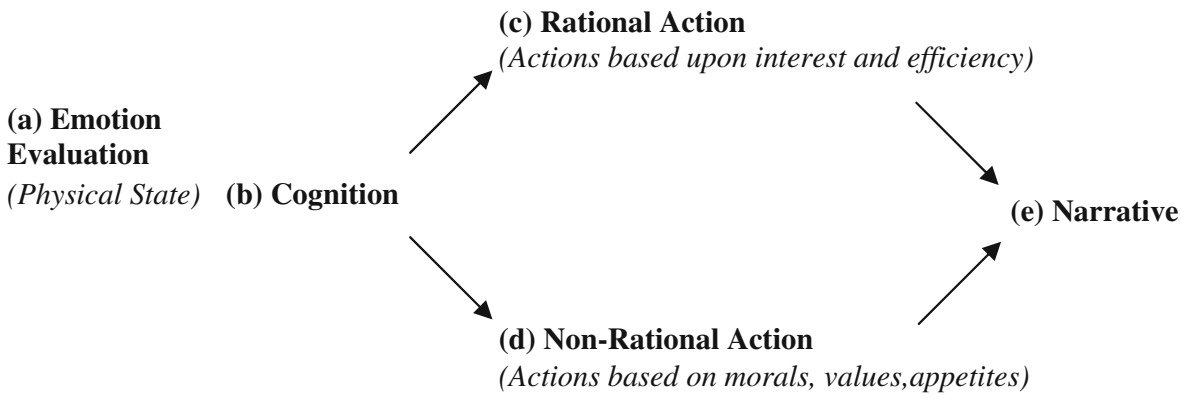

Fig. 1 Emotion and action: analytic possibilities

focuses on its cognitive dimension. Arlie Hochschild's (1979, 1983, 2003) work on emotion rules and management is seminal in this area. The cognitive perspective does not adequately acknowledge that individuals have experiential and physical knowledge of the emotions that they manage or the rules that they follow. Culture and cognition are of course crucial, but so is the physical experience of emotion. Culture and cognition intervene between emotion and action. ${ }^{7}$

Recognizing that emotion begins as a physical state, that it is first about the body and then the mind, is central to theorizing the link between emotion and economic action. Absence of emotion is equilibrium in both physical and economic life. Emotion dis-equilibrates and it is in those moments of dis-equilibration and reequilibration that innovation occurs in social and economic life. Sociology's contribution to the study of emotions and the economy lies in its ability to map the steps between the physical state of emotion and a collective or individual action.

In short, what I am suggesting is that the links between emotions and action may be iterated as a series of pathways. Different disciplines focus upon different pathways; and that recognition of the underlying model as well as the different disciplinary emphases moves forward our understanding of the relation between emotions and social, economic or political life. Figure 1 provides a analytic heuristic of the preceding discussion (see Fig. 1)

I identify five components of an analytic heuristic that models a sociological account of the relation between emotion and action. I draw these components from my analysis of the literature on emotion in neuroscience, philosophy, psychology, economics and sociology that I reviewed in previous essays (Berezin 2002, 2005, 2006). Assembling the components and specifying the possible pathways among them is a first step towards developing an interdisciplinary approach to emotions that identifies the contributions of various disciplines.

The five components are (a) emotion that is experienced as a physical state; (b) cognition the recognition of the emotion; (c) and (d) the characterization of actions that one might take after recognizing an emotion as either rational, that is means end oriented action; or non-rational, that is based upon appetites, values, or morals. Max

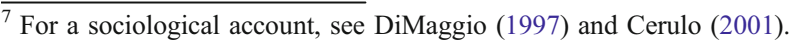


Fig. 2 Emotion and economy: disciplinary paths

\section{Path}

$A b$

Ad

Abd

$A b c$

$B c$ ord

$A b c(e)$ or $a b d(e)$

\section{Discipline}

Neuroscience

Classical Social/EconomicTheory

Moral Philosophy

Economists/Rational Choice

Sociology

Economic Sociology

Weber's forms of social action (Weber 1978, pp. 22-26) inform, but do not define, the distinctions that I draw between rational and non-rational action. The last component (e) is the narrative justification that we give after the fact to explain our actions that may take the form of an economic or moral evaluation of our actions. I added category (e) to the heuristic at the suggestion of sociologist Stephen Vaisey who encouraged me to make moral evaluation a component of cognition. Upon reflection, I decided that narrative evaluation - why I/we took the action that I/we did-was an important analytic category. But that evaluation and cognition were not the same entity and that in temporal terms evaluation would take place after and not before an action. ${ }^{8}$

Different disciplines tend to privilege different pathways in their analyses (see Fig. 2). Neuroscience (Damasio 1994, 1999) tends to focus on path $(a b)$ between emotion and cognition. More recently behavioral economists (Loewenstein 2000) and psychologists (Prinz 2004; Gigerenzer 2007) have begun to explore this link. Gladwell's (2005) short book, Blink attempts to disseminate these ideas to a general audience. While advances in neuroscience offer new directions, they have an $a$ social cast to them that social scientists who are not also natural scientists would not necessarily benefit from emulating. These advances do open the door to future interdisciplinary collaboration between natural and social science.

Classical economic theory from Adam Smith (1776) to Max Weber (1978) took path $(a d)$ and bypassed cognition in their analyses. Classical theorists feared emotion and unruly passions and viewed them as creating societal instability. ${ }^{9}$ While the direct pathway between emotion and action is theoretically possible, it has only historical value and is not analytically viable. Moral philosophers (most notably Nussbaum 2001) have explored path (abd) - that links emotion, cognition and ethical choice. In contrast to moral philosophers, behavioral economists and choice theoretic social scientists problematize emotion and have focused upon the path $(a b c)$ from emotion to cognition to presumably rational choice.

In general, sociologists have bypassed the physiological dimension of emotion and have begun their analyses with cognition and the social processes and rituals that it generates. The sociological focus on rules, roles and emotion management that began with Arlie Hochschild's study of flight attendants $(1979,1983)$ follows path $(b d)$ and sometimes $(b c)$. This approach also finds expression in the works of Goffman (1959) and Collins (1981). In general, we might label this group performative theorists as they focus on rituals and dramaturgy and public display of emotion. In the various iterations of performative theory, emotion is recognized

\footnotetext{
${ }^{8}$ Stephen Vaisey, Personal communication, May 29, 2007 (via email).

${ }^{9}$ See Hirschman's (1977) classic account.
} 
(as a cognition) and at the point that it is either individually or collectively recognized, culture provides a set of socially recognized rules and roles to "manage" the emotion. Emotion management results in a socially acceptable action that may be economically or morally driven. Path $(b c)$ or $(b d)$ is also the space occupied by social psychologists (Lawler 2001, for example) who tend to focus on social exchanges rather than emotion management. While undeniably important, performative theorists and social psychologists tend to point exclusively to micro level processes. These theories tend to attenuate the integrity of emotion by reducing it to a cognitive form, a blip on the psychological radar screen that simply requires the course correction of style, emotion management or interpersonal trust.

A new body of work is emerging in economic sociology that focuses upon the relation between markets and moral evaluation (for example, Somers and Block 2005; Fourcade and Healy 2007). This opens up a new way to bring culture and emotion to bear upon economic sociology. Moral evaluations are narratives about what happened and why - they are the stories that are offered after the fact that expose both the cognitive processes as well as the cultural imperatives that went into a particular course of action. Sociologists (for example, Polletta 2006; Berezin 2009) have pointed to the analytic power of narrative for facilitating and interpreting political outcomes. The analytic power of stories lies in the culturally nuanced justifications for actions that they offer. Evaluative narratives about emotion reveal underlying social facts a la Durkheim, but also in terms of this introduction, economic facts. A robust sociology of emotions whether its focus be economics or some other subfield will follow the path (abce) or (abde).

The articles in this special issue fall on various paths in the above elaborated diagram. Temporality is a central issue in Pixley and Barbalet's contributions. Barbalet provides a novel analysis of trust. Barbalet argues that tust is not an emotion in and of itself, rather it exists in kinship with the feeling of confidencewhich is an emotion. Although trust leads to decisions that are essentially cognitive in nature, our capacity to make those decisions relate to the confidence that we have in our decision making process. Time produces repeated experience that in turn produces a feeling of confidence and in the end trust. Thus, his analysis elaborates paths $a b c$ or $a b d$. Pixley writes about how finance professionals deal with uncertainty in their day to day endeavors. She lays out six constructions that link a felt emotion to an attitude towards time and an institutional rule for emotion management. Her analysis is particularly germane to the 2008 financial crisis. Using her analysis, one could argue that an excessive focus on the present produces the type of "arrogance" and "risk embrace" that facilitated the current crisis. The novelty of Pixley's contribution is her argument that it is "temporal orientation" coupled with cultural style that governs behavior among finance professionals. She advances knowledge on paths bce and bde.

Bandelj borrows from her research on investment finance in the former Eastern Europe and presents a theory of emotions as action and interaction. Focusing on the $a b c$ and $a b d$ path, Bandelj identifies the importance of "improvisation" as a strategy of dealing with the uncertainty inherent in many economic transactions. She justaposes "improvisation" against what she label "situational interaction"- the more frequently identified form of performative economic action. Influenced by Hans Joas, Bandelj makes a strong argument for the "creativity" of economic action 
and urges future research in that direction. Illouz and Finkelman explore how technology in the form of Internet dating sites mediates contemporary marriage markets. Love reputedly governs partner selection in modern times. But the difficulty of finding an appropriate partner for some persons has led to the explosion of dating sites that permit one to screen a large number of potential partners and eliminate them on the most rational of criteria. This essay explores a paradox of modernity. The modern definition of marriage, as opposed to the old one where economic rationales were paramount, is based upon emotion. Yet, the failure to connect requires the mediation of technology to make efficient the modern pursuit of a partner. That efficiency ironically mimics the traditional economic approach to mate selection. In their analysis of contemporary partner selection, Illouz and Finkelman explore path bce.

Acknowledgments The articles collected in this issue originated in a thematic panel at the 2006 American Sociological Meetings in Montreal. We thank participants in the panel Mario Small and Viviana Zelizer; the editors of Theory and Society who agreed to run this issue and the comments of the referees that greatly improved the individual contributions.

\section{References}

Barbalet, J. M. (1998). Emotion, social theory, and social structure. Cambridge: Cambridge University Press.

Barbalet, J. M. (2008). Weber, passion and profits: The protestant ethic and the spirit of capitalism in context. Cambridge, UK; New York: Cambridge University Press.

Berezin, Mabel. (2002). Secure states: towards a political sociology of emotion. In J. Barbalet (Ed.), Emotions and Sociology, pp. 33-52. Oxford: Basil Blackwell.

Berezin, M. (2005). Emotions and the economy. In R. Swedberg \& N. J. Smelser (Eds.), Handbook of Economic Sociology (2nd ed.), pp. 109-127. New York and Princeton: Russell Sage Foundation and Princeton University Press.

Berezin, M. (2006). Acts of Translation: Emotion and Political Communication. Political Communication Report: Volume 16.3. Sponsored by the Political Communications Section of the International Communication Association and the American Political Science Association (http://www.unr.edu/ organizations/pcr/).

Berezin, M. (2009). Illiberal politics in neoliberal times: Culture, security and populislm in the New Europe. UK: Cambridge.

Cerulo, K. A. (2001). Culture in mind: Toward a sociology of culture and cognition. New York: Routledge.

Coleman, J. (1990). The foundations of social theory. Cambridge: Harvard University Press.

Collins, R. (1981). On the microfoundations of macrosociology. American Journal of Sociology, 86(5), 984-1014.

Cook, K. S. (ed). (2001). Trust in society. New York: Russell Sage Foundation.

D’Arms, J., \& Jacobson, D. (2000). Sentiment and value. Ethics, 110, 722-748.

Damasio, A. R. (1994). Descartes' error: Emotion, reason, and the human brain. New York: Harper Collins.

Damasio, A. R. (1999). The feeling of what happens: Body and emotion in the making of consciousness. New York: Harcourt Brace and Co.

Darwin, C. (1872). The expression of the emotions in man and animals. New York: Harper Collins. 1998.

De Santos, M. (2007). Public numbers and fact-totems: Country risk and the cultural life of statistics in Argentina 2001. PhD diss., Yale University.

De Sousa, R. (1980). The rationality of emotions. In A. Rorty (Ed.), Explaining emotions, pp. 125-151. Berkeley: University of California Press.

DiMaggio, P. (1997). Culture and cognition. Annual Review of Sociology, 23, 263-287. 
Douglas, Mary. (1975). Implicit meanings: Essays in anthropology. London; Boston: Routledge \& K. Paul.

Durkheim, E. (1894). The rules of sociological method. Translated by Sarah A. Solovay and John H. Mueller. New York: Free Press of Glencoe. 1964.

Elster, J. (1996). Rationality and Emotions. The Economic Journal, 106(438), 1386-1397.

Elster, J. (1999). Alchemies of the mind: Rationality and the emotions. New York: Cambridge University Press.

Emirbayer, M., \& Goldberg, C. (2005). Pragmatism, Bourdieu, and collective emotions in contentious politics. Theory \& Society, 34, 469-518.

Etzioni, A. (1988). The moral dimension: Towards a new economics. New York: The Free Press.

Fourcade, M., \& Healy, K. (2007). Moral views of market society. Annual Review of Sociology, 33, 285311.

Frank, R. H. (1988). Passions within reason: The strategic role of the emotions. New York: WW. Norton and Company.

Frank, R. H. (1993). The strategic role of emotions: reconciling over-and undersocialized accounts of behavior. Rationality and Society, 5(2), 160-184.

Freud, S. (1905). In A. A. Brill (Ed.), Wit and its relation to the unconscious. London: Routledge. 1999.

Frijda, N. H. (1993). Moods, emotion episodes, and emotions. In M. Lewis \& J. M. Haviland (Eds.), Handbook of emotions, pp. 381-403. New York: Guilford.

Gigerenzer, G. (2007). Gut feelings: The intelligence of the unconscious. New York: Viking.

Gladwell, M. (2005). Blink: The power of thinking without thinking. New York: Little, Brown and Co.

Goffman, E. (1959). The presentation of self in everyday life. New York: Anchor Books.

Greenspan, P. (2000). Emotional strategies and rationality. Ethics, 10, 469-487.

Hall, P. A. (ed). (1989). The political power of economic ideas: Keynesianism across nations. Princeton: Princeton University Press.

Hassoun, Jean-Pierre. (2005). Emotions on the trading floor: Social and symbolic expressions. In K. Knorr-Cetina \& A. Preda (Eds.), The Sociology of Financial Markets, pp. 102-20. New York: Oxford University Press.

Hirschman, A. O. (1977). The passions and the interests: Political arguments for capitalism before its triumph. Princeton: Princeton University Press.

Hochschild, A. R. (1979). Emotion work, feeling rules, and social structure. American Journal of Sociology, 85(3), 551-575.

Hochschild, A. R. (1983). The managed heart: The commercialization of human feeling. Berkeley: University of California Press.

Hochschild, A. R. (2003). The commercialization of intimate life: Notes from home and work. Berkeley: University of California Press.

Illouz, E. (2007). Cold intimacies: The making of emotional capitalism; making of emotional capitalism. Cambridge; Malden: Polity Press.

Illouz, Eva. (2008). Saving the modern soul: Therapy, emotions, and the culture; culture of self-help. Berkeley: University of California Press.

Lawler, E. J. (2001). An Affect Theory of Social Exchange. American Journal of Sociology, 107, 321-52.

Lewis, M. (2008). Panic: The story of modern financial insanity. NY: W.W. Norton.

Loewenstein, G. (2000). Emotions in economic theory and economic behavior. The American Economic Review, 90(2), 426-432.

Manstead, A. S. R., Frijda, N. H., \& Fischer, A. (eds). (2004). Feelings and emotions: The Amsterdam symposium. Cambridge, UK; New York: Cambridge University Press.

Massey, D. S. (2002). A Brief History of Human Society: the Origin and Role of Emotions in Social Life. American Sociological Review, 67, 1-29.

McDermott, R. (2004). The Feeling of Rationality: The Meaning of Neuroscientific Advances for Political Science. Perspectives on Politics, 2, 691-706.

Mendoza, S. P., \& Ruys, J. D. (2001). The beginning of an alternative view of the neurobiology of emotion. Social Science Information, 40(1), 39-60.

Middleton, D. R. (1989). Emotional style: the cultural ordering of emotions. Ethos, 17(2), 187-201.

Neuman, W. R., Marcus, G. E., Crigler, A. N., \& Mackuen, M. (eds). (2007). The affect effect: Dynamics of emotion in political thinking and behavior. Chicago: University of Chicago Press.

Nussbaum, M. C. (2001). Upheavals of thought: The intelligence of emotions. New York: Cambridge University Press.

Parsons, T. (1937). The structure of social action. New York: The Free Press. 1968. 
Pixley, J. (2004). Emotions in finance : Distrust and uncertainty in global markets. Cambridge, U.K.; New York, NY, USA: Cambridge University Press.

Pizarro, D. (2000). Nothing more than feelings? The role of emotions in moral judgment. Journal for the Theory of Social Behavior, 30(4), 355-375.

Polletta, F. (2006). It was like a fever: Storytelling in protest and politics. Chicago: University of Chicago Press.

Prinz, J. J. (2004). Gut reactions: A perceptual theory of emotion. New York: Oxford University Press.

Shiller, R. J. (2000). Irrational exuberance. Princeton: Princeton University Press.

Shweder, R. A. (1993). The cultural psychology of the emotions. In M. Lewis \& J. M. Haviland (Eds.), Handbook of Emotions, pp. 417-431. New York: Guilford.

Smelser, N. J. (1995). Economic rationality as a religious system. In R. Wuthnow (Ed.), Rethinking Materialism, pp. 73-92. Grand Rapids: William Eerdmans Publishing Co.

Smith, A. (1776). The wealth of nations. New York: Knopf. 1991.

Somers, M. R., \& Block, F. (2005). From poverty to perversity: ideas, markets, and institutions over 200 years of welfare debate. American Sociological Review, 70, 260.

Turner, J. H., \& Stets, J. E. (2006). Sociological theories of human emotions. Annual Review of Sociology, 32, 25-52.

Weber, M. (1978). Economy and society, edited by Guenther Roth and Claus Wittich, Vol. II. Berkeley: University of California Press.

Zaloom, C. (2006). Out of the pits: Traders and technology from Chicago to London. Chicago: University of Chicago Press.

Zelizer, V. A. (2005). The purchase of intimacy. Princeton: Princeton University Press.

Mabel Berezin earned her Ph.D. in Sociology at Harvard. She is Associate Professor of Sociology at Cornell University. She is a comparative historical sociologist whose work explores the intersection of political and cultural institutions with an emphasis on modern and contemporary Europe. She is the author of Illiberal Politics in Neoliberal Times: Security, Democracy and Populism in the New Europe (Cambridge University Press 2009) and Making the Fascist Self: The Political Culture of Inter-war Italy (Cornell 1997), which was awarded the J. David Greenstone Prize for Best Book of 1996-1997 in "Politics and History" by the American Political Science Association and named an "Outstanding Academic Book of 1997," by Choice. In addition to numerous articles, review essays, and contributions to edited volumes, she has edited two collaborative volumes: Democratic Culture: Ethnos and Demos in Global Perspective (with Jeffrey Alexander) and Europe Without Borders: Re-mapping Territory, Citizenship and Identity in a Transnational Age (with Martin Schain) (Johns Hopkins 2004). She has been awarded fellowships from the Leverhulme Trust, ASA Fund for Advancement of the Discipline and German Marshall Fund of the United States. 